\title{
Comment on "A Semi-Empirical Approach to Projecting Future Sea-Level Rise"
}

Simon Holgate, ${ }^{1 *}$ Svetlana Jevrejeva, ${ }^{1}$ Philip Woodworth, ${ }^{1}$ Simon Brewer ${ }^{2}$

${ }^{1}$ Permanent Service for Mean Sea Level, Proudman Oceanographic Laboratory, 6 Brownlow Street, Liverpool, L3 5DA, UK

${ }^{2}$ Cemagref, CS 40061, 13182 Aix-en-Provence Cedex 5, France

*To whom correspondence should be addressed; E-mail: simonh@pol.ac.uk.

Rahmstorf (Science, 19 January 2007, 10.1126/science.1135456) presented an approach to the prediction of sea level rise based on a proposed linear relationship between global surface temperatures and the rate of global mean sea level change over the timescales relevant to humans - decades to centuries. We find no such linear relationship and, while agreeing that there is considerable uncertainty in the prediction of future sea level rise, consider that this approach does not meaningfully contribute to quantifying this uncertainty.

Rahmstorf (1) proposed a relationship between global mean surface temperatures (2,3) and the rate of global mean sea level change (4). The approach assumes that "the rate of sea level rise is approximately proportional to the magnitude of warming above the pre-industrial temperature". On this basis sea level is predicted to rise $0.5-1.4 \mathrm{~m}$ above the 1990 level by 2100. These estimates are considerably higher than those published in the IPCC Third Assessment Report (5) and therefore require closer inspection. 
The calculation of the linear relationship between temperature and the rate of sea level change did not explore whether the calculated proportionality constant of $3.4 \mathrm{~mm} / \mathrm{yr} /{ }^{\circ} \mathrm{C}$ applies to the timescales of most relevance (i.e. decades to centuries). Fig. 1(a) below reproduces Fig. 2 in (1). As in (1), both the temperature and sea level timeseries are smoothed with the Monte Carlo Singular Spectrum Analysis method (MC-SSA) (6) to remove energy with periods of less than 15 years. However we have split the data into four epochs which approximately relate to the four dominant periods of the temperature record (Fig. 1(b)) and we have avoided adding the 5 year binning applied in (1) to the 15 year smoothed timeseries as this would further reduce the degrees of freedom. Figure 1(a) clearly demonstrates that no linear relationship exists on a 50 year timescale, that is $50 \%$ of the 100 year period for which predictions are made in (1).

We note that using the model employed

$$
d H / d t=a\left(T-T_{0}\right)
$$

(where $a$ is the proportionality constant, $T$ is the global mean temperature and $T_{0}$ is the previous equilibrium temperature value) with the quoted values of $a=3.4 \mathrm{~mm} / \mathrm{yr} /{ }^{\circ} \mathrm{C}$ and $T_{0}=-0.5{ }^{\circ} \mathrm{C}(1)$ gives $d H / d t=1.7 \mathrm{~mm} / \mathrm{yr}$ with zero (average) change in temperature (i.e. with $T=0$ ). This shows that the mean rate obtained from this model over the past century agrees well with other estimates of sea level rise over the past 100 years (e.g. $(4,7))$. The issue though is whether this model can provide information at shorter periods than the century scale in order that it can be used to predict global sea levels some decades into the future.

A reasonable test of the strength of a model is to be able to predict observations which are not already included in its formulation. To illustrate the non-linearity of the temperature/sea level change relationship we calculate linear coefficients for the first half 
of the observational record and then proceed to predict the remaining observations. We also use the second half of the data set to hindcast sea levels during the earlier part of the record.

To make this testing sensitive to changes on timescales of decades, which are of most interest for prediction, we detrended both the smoothed surface temperatures and the smoothed sea levels for the first and second halves of the data before calculating the annual rates of sea level change (detrending improves the results but does not change their character). We then calculated the linear regression coefficients for the two halves of the data $\left(a_{1}, a_{2}\right)$ along with the equivalent values of $T_{0}$ (i.e. $\left.T_{0_{1}}, T_{0_{2}}\right)$. Finally, to obtain the full $d H / d t$, we added back the linear trend which had been subtracted from the sea levels.

From the above regression we obtain $a_{1}=8.26 \mathrm{~mm} / \mathrm{yr} /{ }^{\circ} \mathrm{C}$ and $T_{0_{1}}=-0.12{ }^{\circ} \mathrm{C}$, for the first half of the data and $a_{2}=6.60 \mathrm{~mm} / \mathrm{yr} /{ }^{\circ} \mathrm{C}$ and $T_{0_{2}}=-0.32{ }^{\circ} \mathrm{C}$ for the second half, compared with $a=3.4 \mathrm{~mm} / \mathrm{yr} /{ }^{\circ} \mathrm{C}$ and $T_{0}=-0.5^{\circ} \mathrm{C}$ from fitting the whole data set. The RMS error over the first half of the record that the data is fitted to is $0.21 \mathrm{~mm}$ and $0.35 \mathrm{~mm}$ over the second half of the record when the data is fitted to that. This is in comparison with $0.62 \mathrm{~mm}$ for the model when fitted to all the data, illustrating that we do indeed obtain a better fit to the data included in the model over the shorter time periods.

The results of this analysis are shown in Fig. 2 which shows that at the 50-100 year timescale the linear relationship has little skill in predicting the observations not included in the original model formulation. Using the coefficients obtained from the first half of the data a trend in sea level of $0.86 \mathrm{~mm} / \mathrm{yr}$ is predicted for the entire 122 year period, whereas using the second half of the data a trend of $1.98 \mathrm{~mm} / \mathrm{yr}$ is calculated. These compare with a trend of $1.49 \mathrm{~mm} / \mathrm{yr}$ for the sea level reconstruction (4) over the period 
1880-2001, implying that the semi-empirical approach is very sensitive to the time period over which the model is formulated.

In conclusion, whilst we agree that there is considerable uncertainty in future projections of sea level change and that model predictions currently appear to under-estimate observations, we do not agree that simplistic projections of the nature presented (1) contribute any understanding of the uncertainties in the non-linear relationships of the climate system.

\section{References and Notes}

1. S. Rahmstorf, Science 315, 368 (2007).

2. J. Hansen, R. Ruedy, M. Sato, R. Reynolds, Geophysical Research Letters 23, 1665 (1996)

3. R. Reynolds, N. Rayner, T. Smith, D. Stokes, W. Wang, Journal of Climate 15, 1609 (2002).

4. J. Church, N. White, Geophysical Research Letters 33, L01602 (2006).

5. J. Church, et al., Climate Change 2001: The Scientific Basis. Contribution of Working Group I to the Third Assessment Report of the Intergovernmental Panel on Climate Change., J. Houghton, et al., eds. (Cambridge University Press, Cambridge, UK, 2001), chap. 11, pp. 639-694.

6. J. Moore, A. Grinsted, S. Jevrejeva, EOS 86, 226 (2005).

7. S. Holgate, Geophysical Research Letters 34, L01602 (2007). 
8. We would like to thank S. Williams for productive conversations in the preparation of the manuscript. This work is funded by the UK Natural Environment Research Council. 
(a)

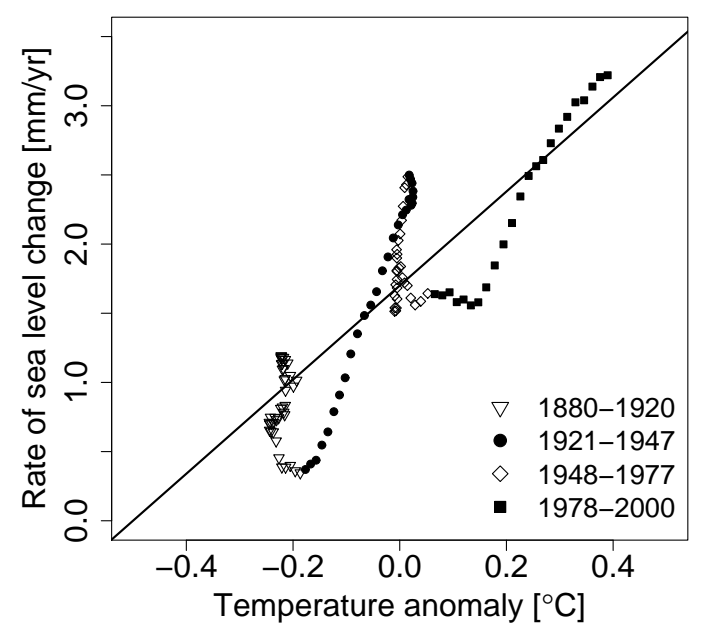

(b)

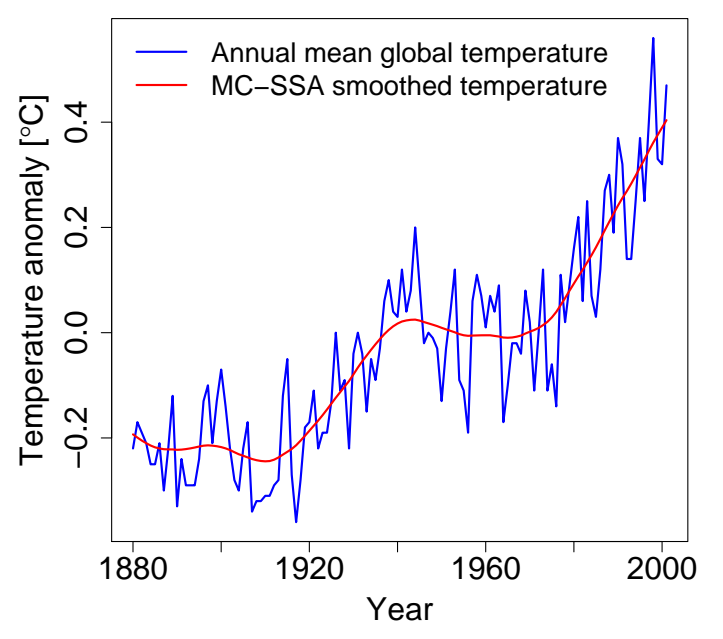

Fig. 1. (a) The relationship of the rate of global mean sea level rise (4) to global mean surface temperature $(2,3)$ with the data divided into four epochs each showing a different relationship between the variables. This figure is a reproduction of Fig. 2 in (1) but without the binning into 5 year averages in order to better illustrate the data clustering. (b) The global mean surface temperature record (2,3), annual data and smoothed using the MC-SSA method (6). The four epochs described in (a) relate to the four sections of the temperature record that can be clearly seen. 


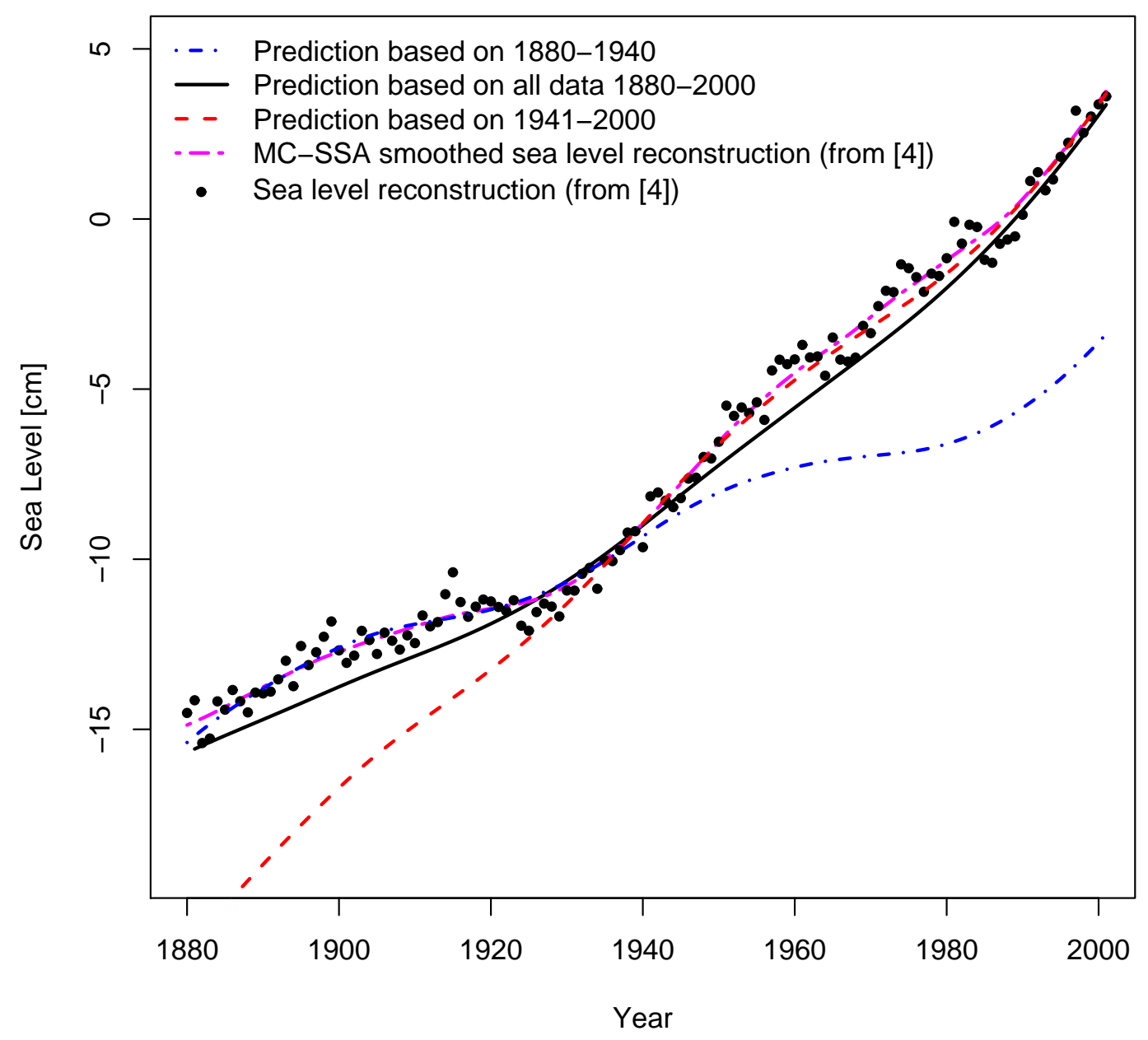

Fig. 2. Hindcasts of the global mean sea level based on linear rates calculated from the full data set as in (1) and based on rates calculated from the first and second halves of the reconstructed sea level record (4). Based on the first half of the record the mean rate of sea level rise is $0.86 \mathrm{~mm} / \mathrm{yr}$ and $1.98 \mathrm{~mm} / \mathrm{yr}$ based on the second half of the record. The mean rate for the 1887-1994 period based on the sea level reconstruction (4) is 1.49 $\mathrm{mm} / \mathrm{yr}$. There is clearly little skill in prediction of the observational record on the 50-100 year timescale relevant to this work. 